\title{
A Prospective Randomized Controlled Trial to Assess the Effect of Intravenous versus Oral Iron Therapy in the Treatment of Orthopaedic Preoperative Anaemia
}

Alhossain Khalafallah', ${ }^{1,2 *}$, Abdul Majeed Al-Barzan ${ }^{3}$, Johan Chan ${ }^{2}$, Mei Fen Sung ${ }^{2}$, Gerald Bates $^{1,3}$, Kiran DK Ahuja $^{3}$, John C Batten ${ }^{4}$ and Bernie Einoder ${ }^{4}$

${ }^{1}$ Launceston General Hospital, Launceston, Tasmania, Australia

${ }^{2}$ Clinical School of Medicine, Launceston, University of Tasmania, Australia

${ }^{3}$ School of Human Life Sciences, University of Tasmania, Australia

${ }^{4}$ Department of Orthopaedic Surgery, Launceston General Hospital, Launceston, Tasmania, Australia

\begin{abstract}
Background: Improving preoperative anaemia is associated with a better surgical outcome. There is lack of data regarding treatment of preoperative anaemia with intravenous versus oral iron.

Objective: Assessment of efficacy of oral iron sulphate versus a single intravenous iron polymaltose and subsequent effect on perceived quality of life in both treatment groups.

Patients and methods: We conducted a prospective randomised controlled trial with iron therapy for the treatment of Iron Deficiency Anaemia (IDA) patients who were undergoing elective joint arthroplasty. At a single institution, we recruited 44 patients who were randomized to a single intravenous iron polymaltose infusion $(16 / 22)$ versus oral daily iron sulphate (17/22). Median age was 68 years (range, 45-91) with a male to female ratio of 14:19.
\end{abstract}

Results: After iron therapy, the immediate mean preoperative $\mathrm{Hb}$ was increased to $128 \mathrm{~g} / \mathrm{L}(\mathrm{SD} \pm 11.05)$ in the IV iron group versus $118 \mathrm{~g} / \mathrm{L}(S D \pm 9.23)$ in the oral iron group ( $p=0.01)$ compared to $116 \mathrm{~g} / \mathrm{L}(\mathrm{SD} \pm 8.46)$ in the control group $(p=0.001)$. The average length of stay in the hospital for the IV iron group was 6 days $(S D \pm$ $2.51)$ compared to 8 days $(S D \pm 3.62)$ in the oral iron group and 8 days $(S D \pm 4.18)$ in the control group $(p=0.04)$. Average transfused blood units were 1.5 units in the IV iron group versus 2 units in the oral iron group $(p=0.09)$ and 2.4 units in the control group $(p=0.04)$. There was a significant improvement of the symptoms of anaemia $(p=0.03)$ after treatment in the IV versus oral iron group with further improvement at 3 months follow-up $(p=0.003)$.

Conclusion: Our data suggest that IV iron therapy is superior to oral iron in improving preoperative $\mathrm{Hb}$ and hence overall outcome for patients with preoperative IDA. Further trials that aim to improve and optimize preoperative and postoperative $\mathrm{Hb}$ are warranted.

Keywords: Preoperative anaemia; Oral iron; Intravenous iron; Orthopaedic surgery; Blood transfusion; Outcome; Quality of life

\section{Introduction}

Both pre and postoperative anaemia are highly prevalent in surgical patients $[1,2]$. Depending on the type of surgery, underlying disease and the definitions of anaemia, about $11 \%$ to $76 \%$ of surgical patients may present with pre-operative anaemia $[3,4]$. Recently, there has been increasing evidence to suggest that pre-operative anaemia can lead to an increased risk of peri-operative adverse outcomes such as increased post operative infections, increase the requirement for blood transfusion, increase of hospital Length of Stay (LoS) and increased overall morbidity and mortality [5-7]. In addition, evidence has shown that pre-operative anaemia increases the chance of receiving unnecessary allogeneic blood transfusion with its consequences when compared to patients with a normal haemoglobin level [5-7]. This is considered as an independent risk factor that increases peri-operative adverse outcomes [5,7]. Many studies demonstrated that there was an increased risk of postoperative mortality and morbidity including pulmonary and infectious complications after receiving intraoperative blood transfusions [8-10]. Thus, there has been an increased emphasis on the correction of preoperative anaemia to improve the patient's outcome and decrease the need for allogeneic blood transfusion.

This trial was designed to compare the efficacy of two interventions designed to treat pre-operative anaemia: standard oral iron (iron sulphate) and a single intravenous iron therapy (iron polymaltose) Primary endpoint was the immediate pre-operative haemoglobin and secondary endpoints were post-operative complications in terms of blood transfusion requirement, incidence of infection, and length of hospital stay. Furthermore Quality of Life (QoL) measurements were collected, which determined energy level, activity, symptoms of anaemia and the wellbeing of patients via a modified SF36 health questionnaire at initial enrolment, immediate preoperative period (after treatment), 3 and 6 months post-operatively.

\section{Patients and Methods}

\section{Design overview}

A prospective randomised controlled trial was conducted between

*Corresponding author: Alhossain Khalafallah, M.D., Associate Professor, Consultant Haematologist, The Launceston General Hospital, Launceston Tasmania, 7250, Australia, Tel: +61-3-63487111; Fax: +61-3-63353388; E-mail: khalafallah@dhhs.tas.gov.au/ alhossain@yahoo.com

Received May 13, 2012; Accepted July 30, 2012; Published August 01, 2012

Citation: Khalafallah A, Al-Barzan AM, Chan J, Sung MF, Bates G, et al. (2012) A Prospective Randomized Controlled Trial to Assess the Effect of Intravenous versus Oral Iron Therapy in the Treatment of Orthopaedic Preoperative Anaemia. J Blood Disorders Transf 3:127. doi:10.4172/2155-9864.1000127

Copyright: (c) 2012 Khalafallah A, et al. This is an open-access article distributed under the terms of the Creative Commons Attribution License, which permits unrestricted use, distribution, and reproduction in any medium, provided the original author and source are credited. 
Citation: Khalafallah A, Al-Barzan AM, Chan J, Sung MF, Bates G, et al. (2012) A Prospective Randomized Controlled Trial to Assess the Effect of Intravenous versus Oral Iron Therapy in the Treatment of Orthopaedic Preoperative Anaemia. J Blood Disorders Transf 3:127. doi:10.4172/2155-9864.1000127

February 2008 and September 2010 at the Launceston General Hospital (LGH), a tertiary referral centre for Northern Tasmania, Australia. An informed consent form was obtained from all patients according to the Code of Ethics. The trial was approved by the Tasmania Human Research Ethics Committee and was registered in the Australian New Zealand Clinical Trials Registry at http://www.ANZCTR.org.au under ACTRN12609000596202. The web page of the trial is as following: http://www.ANZCTR.org.au/ACTRN12609000596202.aspx and in the World Health Organization (WHO) website: http://www.who.int/ trialsearch/trial.aspx?trialid=ACTRN12609000596202.

The primary objective of this study was to determine the effectiveness of a single intravenous (IV) iron polymaltose infusion compared to daily oral iron in the treatment of pre-operative anaemia. The primary endpoint was the immediate pre-operative haemoglobin. Secondary objectives were to assess tolerability, safety of iron therapy as well as quality of life of these patients. Furthermore an assessment of post-operative complications such as post operative infection rate, length of hospital stay and number of transfused packed Red Blood Cell (RBCs) units was conducted.

Quality of life and patient's wellbeing were assessed during preoperative and post-operative periods via a modified version SF36 questionnaire. The modifications incorporated assessment of the physical status, energy levels, symptoms of anaemia and well-being component scale values at each of the time points.

\section{Participants}

We prospectively screened patients who were scheduled to undergo elective joint arthroplasty at the LGH between February 2008 and September 2010 and those with a haemoglobin level of less than 120 $\mathrm{g} / \mathrm{L}$ for females and $<140 \mathrm{~g} / \mathrm{L}$ for males and above $90 \mathrm{~g} / \mathrm{L}$ were eligible for the trial. Patients underwent additional investigations with iron, vitamin B12 and folate studies. If patients had any causes of anaemia apart from iron deficiency, they were excluded from the trial (Figure 1). Iron deficiency was defined by ferritin level $<30 \mathrm{mcg} / \mathrm{L}$ (normal 30-464), while low iron stores were defined by ferritin levels below $100 \mathrm{mcg} / \mathrm{L}$. The causes of iron deficiency were investigated separately. Patients with positive occult blood were transferred for Gastroenterologist (GIT) investigation with appropriate upper and lower GIT endoscopy. Patients with malignancy were excluded from the trial. The study was explained in detail, and a written informed consent was obtained from all subjects.

We recruited 44 patients who presented with low $\mathrm{Hb}$ and low iron

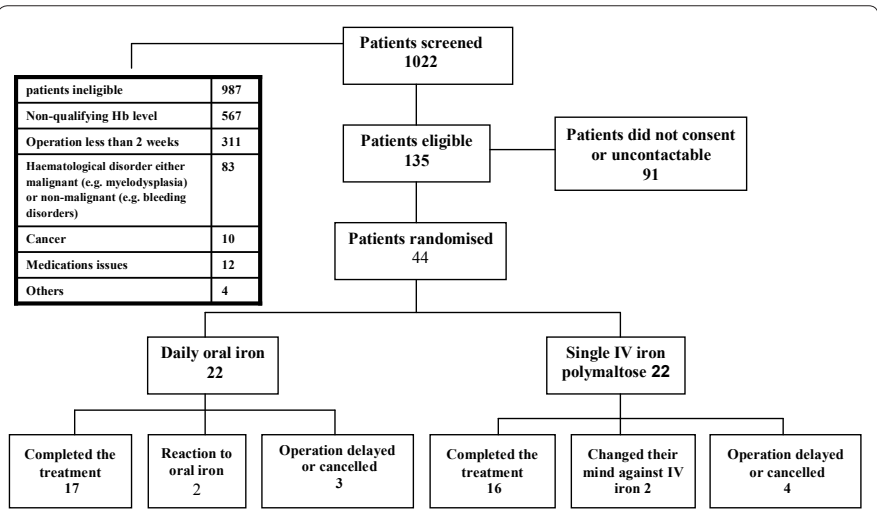

Figure 1: Trial flow diagram. stores. The median age was 68 years. The median time between the treatment and surgery was 22 days (range, 14-38).

Exclusion criteria included patients with specific causes for anaemia or haemoglobin below $86 \mathrm{~g} / \mathrm{L}$ as well as patients with a documented iron overload status. None of the patients recruited in this study had a concomitant diagnosis of cancer. Due to ethical concerns, patients with severe Iron Deficiency Anaemia (IDA) with $\mathrm{Hb}$ level $<86 \mathrm{~g} / \mathrm{L}$ were offered IV iron without randomization and were excluded from the trial. A pilot study with the addition of vitamin B12 1000 mcg intramuscular single injection 3-4 weeks prior to surgery was considered within the original trial arms. Patients were randomly assigned to vitamin B12 versus no treatment in each active treatment group. However, due to lack of differences in the both treatments groups, the pilot study was aborted.

\section{Measurement of $\mathrm{Hb}$ and iron studies}

The blood samples were taken from the participants in the morning. Only fresh blood samples were analysed at the Australian National Association Testing Authority accredited laboratory at the LGH at the time of presentation to clinics. The blood samples of all participants were processed within 2 hours of collection as per turnaround time for the laboratory. All variables were determined consecutively. The serum iron and transferrin were measured on an Abbott Architect c8000 autoanalyzer (Abbott, NYSE, USA). The serum ferritin was measured on an Ortho Diagnostics ECi Immunoassay analyser (Ortho Clinical Diagnostics, NJ, USA) using Ortho Diagnostics Ferritin reagent (twostep immunometric). The $\mathrm{Hb}$ was measured by Australia National Testing Authority accredited LGH standard reference laboratory using a Beckman Coulter LH-500 (Beckman Coulter, CA, USA). Hb and iron studies were performed at baseline, and $\mathrm{Hb}$ was measured immediately preoperatively ( 4 weeks after commencement of treatment) as well as at 48 hours and 6 weeks post operatively.

\section{Randomization and interventions}

Informed consent was obtained from all patients and treatment was randomised in blocks of 4 by the Pharmacy Department, LGH. The oral iron therapy comprised $325 \mathrm{mg}$ of iron sulphate (elemental iron $105 \mathrm{mg}$ ) daily while the intravenous iron infusion comprised of a single dose iron polymaltose (Ferrosig, Sigma Pharmaceuticals, Australia) within a few days after enrolment. In a specially-designed questionnaire addressing dietary iron intake, there were no significant differences between the two groups, in particular there were no strict vegans among the recruited patients. Patients assigned to IV iron polymaltose received a $100 \mathrm{mg}$ test-dose dissolved in $100 \mathrm{ml}$ normal saline infused over 30 minutes after a premedication with $4 \mathrm{mg}$ IV dexamethasone and oral antihistamine. Clinical observation and vital signs were assessed initially and every $15 \mathrm{~min}$ from the start of the infusion. If the test-dose was well tolerated, the remainder of the iron polymaltose dose was infused in $500 \mathrm{ml}$ normal saline over 90 minutes [11].

The total dose of IV iron polymaltose was calculated according to the patient's body weight at preadmission visit and entry $\mathrm{Hb}$ level according to the product guidelines; iron dose in $\mathrm{mg}(50 \mathrm{mg}$ per $1 \mathrm{ml}$ ) = body weight (maximum $90 \mathrm{~kg})$ in $\mathrm{kg} \times($ target $\mathrm{Hb}(120 \mathrm{~g} / \mathrm{L})$ - actual $\mathrm{Hb}$ in $\mathrm{g} / \mathrm{L}) \times$ constant factor $(0.24)+$ iron $\operatorname{depot}(500)$. IV iron was well tolerated and there were no side effects recorded.

The type of anaesthesia performed in all cases of Total Knee Replacement (TKR) and in $80 \%$ of cases of Total Hip Replacement (THR) was epidural anaesthesia. This may have contributed to reduce 
Citation: Khalafallah A, Al-Barzan AM, Chan J, Sung MF, Bates G, et al. (2012) A Prospective Randomized Controlled Trial to Assess the Effect of Intravenous versus Oral Iron Therapy in the Treatment of Orthopaedic Preoperative Anaemia. J Blood Disorders Transf 3:127. doi:10.4172/2155-9864.1000127

Page 3 of 6

blood loss as it has been reported that the neuraxial blocks have less blood loss in orthopaedic surgery [12]. No fibrinolytic agents were used in our cohort of patients as per our standard practice. None of the patients studied was vegetarian. They had been advised to consume food as they normally did prior to the surgery.

\section{Control group}

A dedicated age and sex matched control group with patients who underwent elective joint arthroplasty; TKR (7) and THR (11) and presented with the same trial inclusion criteria was included. These patients were ineligible or declined active participation in the trial, however, they agreed and were consented to allow the researcher to follow up and collect their data without any active intervention. The patients' data served as a control and was compared to the active intervention arms' data. For those, only preoperative preadmission $\mathrm{Hb}$ as well as post operative $\mathrm{Hb}$ were measured routinely and were available for the study purposes.

\section{Statistical analysis}

A multivariate analysis of the data in correlation with pre- and postoperative $\mathrm{Hb}$, length of hospital stay and outcome was performed using STATA Soft software. Numerical data was summarised with means and Standard Deviations (SD). Data between the three groups was compared using repeated measures mixed methods ANOVA. Assumption of linear regression was checked and if necessary, data was reanalysed using ordinal logistic regression. P value $<0.05$ was considered as statistically significant. Results associated with laboratory parameters were expressed as odds ratios, with 95\% confidence intervals.

\section{Results}

Among 44 recruited patients with preoperative anaemia, there was 33 patients completed the trial. The male to female ratio was 14:19 with a median age of 68 years (range, 45-91). There were 17 out 22 patients completed the oral iron treatment versus 16 out of 22 patients in the IV iron group. All patients were recruited approximately 3-4 weeks prior to the elective surgery for total knee replacement (16) and total hip replacement (17). Median initial $\mathrm{Hb}$ at trial entry for all patients was $110 \mathrm{~g} / \mathrm{L}$ (range, 90-130) that improved after treatment to $122 \mathrm{~g} / \mathrm{L}$ (96-149) $(\mathrm{p}=0.01)$. In the control group, preoperative $\mathrm{Hb}$ was $116 \mathrm{~g} / \mathrm{L}$ (range, 92-135 g/L). The average length of stay in the hospital for the IV iron group was 6 days ( $\mathrm{SD} \pm 2.51$ ) versus 8 days $(\mathrm{SD} \pm 3.62)$ in the oral iron group $(\mathrm{p}=0.06)$ compared to 8 days $(\mathrm{SD} \pm 4.18)$ in the control group $(\mathrm{p}=0.04)$. An average transfused blood unit was 1.5 units $(\mathrm{SD} \pm$ $0.58)$ in the IV iron group (median 2) versus 2.2 units $(S D \pm 0.83)$ in the oral iron group (median 2$)(\mathrm{p}=0.09)$ and 2.4 units $(\mathrm{SD} \pm 0.73)$ in the control group (median 3$)(\mathrm{p}=0.04)$. The trigger for blood transfusion was a $\mathrm{Hb}$ level $<80 \mathrm{~g} / \mathrm{L}$ in the immediate post operative period. The percentage of patients receiving blood transfusion in the IV iron group was $25 \%$ versus $29 \%$ in the oral iron group versus $33 \%$ in the control group.

Immediate preoperative $\mathrm{Hb}$ (after treatment) was increased to 128 $\mathrm{g} / \mathrm{L}$ (111-149) in the IV iron group compared to $118 \mathrm{~g} / \mathrm{L}$ (96-137) in the oral iron group. Post operative Hb (48 hours) averaged $92 \mathrm{~g} / \mathrm{L}$ (SD $\pm 11.05)$ in the IV iron group versus $87.75 \mathrm{~g} / \mathrm{L}(\mathrm{SD} \pm 11.73)$ in the oral iron group versus $87.91 \mathrm{~g} / \mathrm{L}(\mathrm{SD} \pm 12.72)$ in the control group (Table 1). The 48 hours post operative $\mathrm{Hb}$ results were not significant among all three groups. At six weeks post operative $\mathrm{Hb}$ level showed a maintained improvement in the IV iron group to $120 \mathrm{~g} / \mathrm{L}(\mathrm{SD} \pm 13.80)$ versus 108 $\mathrm{g} / \mathrm{L}( \pm 11.15)$ in the oral iron group $(\mathrm{p}=0.01)$ (Table 1$)$.

\section{Quality of life assessment}

A truncated modified SF 36 quality of life questionnaire comprising of 24 questions addressing four domains of QoL relevant to the study; anaemia symptoms scale, energy level scale, activities level scale and wellbeing scale was conducted for the patients included in the study. The module was developed according to the guidelines of SF36 [13,14]

The questionnaire was presented to all patients at initial interview, at the time of enrolment and thereafter prior to surgery and conducted 3 and 6 months after surgery via phone interview by a research assistant who underwent special training with the SF36 modified module.

Levels of activity, energy as well as symptoms of anaemia and the participants well being were analysed and scored according to each question in a scale between 5 to 40 in the activity and well being, where a score of 40 indicates maximum activity and well being and a score of 5 was the least. Energy scale was between 5 and 35, where score of 35 reflects maximum energy and score of 5 the least. The symptoms scale was between 5 and 25, where a score of 5 corresponded to maximum presence of symptoms of anaemia while a score of 25 means the least symptoms of anaemia (Figure 2).

There was a significant improvement of symptoms of anaemia in the IV iron group versus oral iron group after commencement of the treatment as measured in the immediate preoperative period $(\mathrm{p}=0.03)$ that further improved at 3 months and was maintained at 6 months follow up ( $\mathrm{p}=0.003)$. There was no significant difference in terms of wellbeing, activity and energy levels at all time points between the two groups, albeit with a tendency for improvement in the IV iron versus oral iron that did not reach a significant statistical difference. Intergroup analysis revealed that there was a significant improvement in the activity and energy levels as compared between the initial assessments and the three months follow-up period in each group separately. These differences were greater in the IV group compared to the oral iron group without reaching a significant difference. However this analysis could be biased as the patients probably were mobilising better after the joint arthroplasty and hence it reflected on their positive assessment

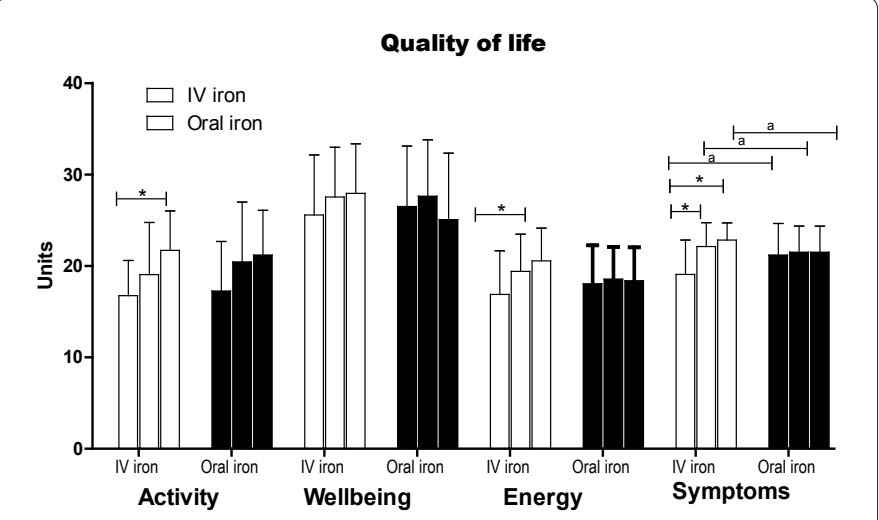

*Significantly different from the initial pre-operative assessment aSignificantly different from the IV group

Bars are initial assessment, immediate preoperative assessment and 3 month follow-up.

Activity-scale: Normal activities 40 and least activity 5. Wellbeing-scale: Best wellbeing 40 and least wellbeing 5. Energy-scale: Normal energy-level 35 and least 7. Symptoms-scale: No symptoms 25 and maximum symptoms 5 . Figure 2: Quality of life data for both intervention groups. 
Citation: Khalafallah A, Al-Barzan AM, Chan J, Sung MF, Bates G, et al. (2012) A Prospective Randomized Controlled Trial to Assess the Effect of Intravenous versus Oral Iron Therapy in the Treatment of Orthopaedic Preoperative Anaemia. J Blood Disorders Transf 3:127. doi:10.4172/2155-9864.1000127

three months after the operation with a corresponding increase of their activities. The patients' wellbeing did not change significantly between the two groups and also in the intergroup analyses at all time points. Assessment of infection complications during and after the operative procedure showed no statistical significance between patients in both treatment groups.

\section{Cost-effectiveness analysis}

An approximate figure for the cost of one unit of packed RBC according to unpublished data from the Red Cross, Australia is estimated around \$700 AUD including processing, delivery and administration. However, the predicted cost of transfusing a blood unit in the hospital per-RBC-unit is calculated between $\$ 522$ and $\$ 1183$ USD (mean, $761 \pm 294$ ) in recent studies $[15,16]$. In addition the cost of nursing staff and materials used to administer this unit is approximately \$300 AUD at our hospital subject to a significant increase depending on occurrence of complications [16]. The cost of one iron sulphate tablet is approximately USD $\$ 0.2-0.3$, so the average cost for 4 weeks is calculated to be $\$ 9$. The cost of an iron polymaltose ampoule containing $500 \mathrm{mg}$ is $\$ 50$, so the average treatment cost for $100 \mathrm{mg}$ is $\$ 100$. In Australia the cost of the outpatient hospital visit and nursing time for the IV iron, adds approximately $\$ 100$ to the drug cost subject to variations according to different health systems (1 AUD is equivalent to 1 USD at the time of analysis). In our study we saved approximately between 2-5 units of blood weekly, as projected in our cohort of patients by employing IV iron therapy compared to control group. This will result in an approximate yearly cost-saving between USD $\$ 100,000$ and $\$ 200,000$ to the health system. It is worth noting that the amount of cost-saving per year is proportional to the amount of reduction of transfusion of blood units. Furthermore, the cost of average Length of Hospital Stay (LOS) is approximately $\$ 800$ AUD per day which is subject to increases according to different treatments. Thus, if the LOS per patient is shortened by an average 2 days as a result of our study in the IV iron group, it translates to a saving value of $\$ 200,000$ for 100 patients per year in addition to a similar amount of saved costs for blood units. Hence, we anticipate a total yearly saving of \$400,000 AUD in a 300-bed hospital, considering the total number of operations per year with an estimated true anaemia rate based on our cohort of patients in addition to the number of blood units that have been required during and after the operation versus the cost per unit and day of hospital stay compared to the control group. However, we should emphasise that this study is not designed specifically to address the cost issues of LOS or transfused RBCs. Further specific studies to address this important cost issue are warranted.

\section{Discussion}

Reports have demonstrated that about $35 \%$ of patients undergoing joint arthroscopy or non cardiac surgery have anaemia while about $76 \%$ of patients with Dukes stage D colon cancer have low haemoglobin levels before surgery [17-19]. Furthermore, previously undiagnosed anaemia is common in elective orthopaedic surgical patients and is associated with increased likelihood of blood transfusion and increased perioperative morbidity and mortality [20]. Therefore, a multidisciplinary panel of experts was summoned through the Network for Advancement of Transfusion Alternatives (NATA) with the aim of developing practice guidelines for management of preoperative anaemia in elective orthopaedic surgery [20]. This indicates that there is an increasing interest among health providers for optimizing the management of pre-operative anaemia with the aim of improving outcome and reducing blood transfusion, especially with the current shortage of blood supply. Moreover, many cases of preoperative anaemia are associated with depleted iron stores [19-23].

A recent systematic review showed that the mean prevalence of anaemia in patients undergoing elective knee or hip arthroplasty was $24 \%$ compared to $45 \%$ in those undergoing surgery because of a hip fracture in elderly populations [1]. It has been observed that the prevalence of anaemia increases among elderly populations, so the proportion of older patients who undergo major orthopaedic surgery is rising progressively, with a high prevalence of anaemia (43\%) observed in a retrospective cohort of 57,636 veterans aged 65 years or older who underwent major elective and non-elective orthopaedic surgery $[24,25]$.

As an explanation for the prevalence of IDA among this cohort of patients, elderly patients usually suffer from osteoarthritis and therefore require NSAIDs that may cause occult GIT- blood loss. Also, lack of iron absorption may happen secondary to atrophic gastritis or antacid therapy commonly administered in this cohort of patients. In our study $60 \%$ of patients received NSAIDs mainly because of osteoarthritic

\begin{tabular}{|c|c|c|c|}
\hline Variable & IV & Oral & Control \\
\hline Length of Stay (days) $^{1}$ & $6.24 \pm 2.51$ & $\begin{array}{l}8.0 \pm 3.62 \\
(p \text { value against IV } 0.06)\end{array}$ & $\begin{array}{l}7.72 \pm 4.18 \\
(p \text { value against IV } 0.04) \\
(p \text { value against oral } 0.83)\end{array}$ \\
\hline $\begin{array}{l}\text { Immediate pre-operative } \mathrm{Hb} \text { (post- } \\
\text { treatment) }\end{array}$ & $128.47 \pm 11.05$ & $\begin{array}{l}118.44 \pm 9.23^{*} \\
(p \text { value against IV }=0.01)\end{array}$ & $\begin{array}{l}116 \pm 8.46^{*} \\
(p \text { value against IV }=0.001 \\
(p \text { value against oral } 0.51)\end{array}$ \\
\hline $48 \mathrm{Hour} \mathrm{Hb}$ & $\begin{array}{l}92.65 \pm 12.57^{\mathrm{a}} \\
P \text { value against pre op }<0.001\end{array}$ & $\begin{array}{l}87.75 \pm 11.73^{a} \\
\text { Not different from IV } p=0.35 \\
P \text { value against pre op is }<0.001\end{array}$ & $\begin{array}{l}87.91 \pm 12.72^{\mathrm{a}} \\
\text { Not different from IV } p=0.26 \\
\text { Not different from oral } p=0.62 \\
P \text { value against pre op }=<0.001\end{array}$ \\
\hline 6 week postoperative $\mathrm{Hb}$ & $\begin{array}{l}120.88 \pm 13.80^{\text {ab }} \\
\text { P value against pre op }<0.001 \\
P \text { value against } 48 \mathrm{hr} \mathrm{Hb}<0.001\end{array}$ & $\begin{array}{l}108.94 \pm 11.15^{\mathrm{ab}} \\
\text { Not different from IV } p=0.7 \\
P \text { value against preop is } 0.01 \\
P \text { vale against } 48 \mathrm{hr} \mathrm{Hb} \text { is }<0.001\end{array}$ & Not available \\
\hline $\begin{array}{l}\text { No. of Packed RBCs units given in the } \\
\text { peri-operative period }\end{array}$ & $1.5 \pm 0.58$ & $\begin{array}{l}2.22 \pm 0.83 \\
P \text { against IV }=0.09\end{array}$ & $\begin{array}{l}2.44 \pm 0.73^{*} \\
P \text { against IV }=0.04 \\
P \text { against oral } 0.50\end{array}$ \\
\hline
\end{tabular}

Results presented as mean and standard deviation

1Data analysed with ordinal logistic regression. *Significantly different from IV group

aSignificantly different from Preoperative $\mathrm{Hb}$ in the same intervention group; 'bignificantly different from 48 hours $\mathrm{Hb}$ in the same intervention.

Table 1: Comparison between both intervention groups and control group in terms of $\mathrm{Hb}$ levels at different trial points entry, length of hospital stay and number of transfused packed RBCs units. 
Citation: Khalafallah A, Al-Barzan AM, Chan J, Sung MF, Bates G, et al. (2012) A Prospective Randomized Controlled Trial to Assess the Effect of Intravenous versus Oral Iron Therapy in the Treatment of Orthopaedic Preoperative Anaemia. J Blood Disorders Transf 3:127. doi:10.4172/2155-9864.1000127

Page 5 of 6

\begin{tabular}{|c|c|c|c|c|c|}
\hline Name of the IV iron preparation & Status of registration & Indications & Test dose & Duration of infusion & $\begin{array}{l}\text { Maximum dose in single } \\
\text { infusion }\end{array}$ \\
\hline $\begin{array}{l}\text { Ferumoxytol (Feraheme }{ }^{\circledR}, A M A G \\
\text { Pharmaceuticals, Inc., USA) }\end{array}$ & FDA-approved & $\begin{array}{l}\text { Treatment of iron-deficiency } \\
\text { anaemia in adult patients } \\
\text { with CKD* }\end{array}$ & None & 1 minute & Maximum dose $510 \mathrm{mg}$ \\
\hline $\begin{array}{l}\text { Ferric carboxymaltose (Ferinject }{ }^{\circledR} \text {, Vifor } \\
\text { Pharma, Glattbrugg, Switzerland) }\end{array}$ & $\begin{array}{l}\text { Approved in Europe, } \\
\text { FDA-approval is sought }\end{array}$ & $\begin{array}{l}\text { Treatment of iron-deficiency } \\
\text { anaemia }\end{array}$ & None & 15 minutes & $\begin{array}{l}\text { Maximum dose } 1000 \mathrm{mg} \text {. } \\
\text { IV rate is } 20 \mathrm{mg} / \mathrm{kg}\end{array}$ \\
\hline Ferrosig® (Sigma Pharmaceuticals, USA) & $\begin{array}{l}\text { Approved in Europe, } \\
\text { and by FDA }\end{array}$ & $\begin{array}{l}\text { Treatment of iron-deficiency } \\
\text { anaemia }\end{array}$ & Yes & 120 minutes & No maximum dose \\
\hline $\begin{array}{l}\text { Iron isomaltoside (MonoFer®, } \\
\text { Pharmacosmos A/S, Holbaek, Denmark) }\end{array}$ & $\begin{array}{l}\text { Approved in Europe } \\
\text { FDA-approval is sought }\end{array}$ & $\begin{array}{l}\text { Treatment of iron-deficiency } \\
\text { anaemia in adult patients } \\
\text { with CKD* }\end{array}$ & None & 60 minutes & $\begin{array}{l}\text { No maximum dose } \\
\text { IV rate is } 20 \mathrm{mg} / \mathrm{kg} \text { body } \\
\text { weight }\end{array}$ \\
\hline
\end{tabular}

FDA: Food and Drug Administration; CKD: Chronic Kidney Disease

${ }^{*}$ Extended approval is sought.

Table 2: Current intravenous iron preparations including new agents

pain and 35\% were complaining of gastro-oesophageal reflux disease that required ongoing treatment with proton pump inhibitors and or antacids.

The use of recombinant human erythropoietin or autologous blood transfusion pre-operatively have been suggested as ways to manage preoperative anaemia [26,27]. A review of the evidence based outcomes of the different supplementations in hip and knee surgery suggested that iron therapy, both oral and intravenous have been shown to reduce the need for allogeneic blood transfusion and significantly reduced the post-operative infection rate [28-31]. In our hand, IV iron was superior to oral iron and both have improved the preoperative $\mathrm{Hb}$, nevertheless, with a greater and significant effect in the IV iron group. This also resulted in a reduction of the number of transfused PRBCs compared to the control $(p=0.04)$. However, there were no significant changes on the infection rate among the three groups.

Furthermore, there was a potential for reduction of length of stay in the IV iron group compared to oral iron and control group ( $\mathrm{p}=0.06$ and $p=0.04$ respectively). A systemic review comparing the evidence of administering erythropoietin with iron supplements to an active control group of either iron supplementation or cell salvage [26,30], showed that the clinical outcomes of post-operative infections, length of stay and 30 day mortality were generally not significant when compared to the active control group in these studies.

Altogether, our study is showing that IV iron polymaltose is well tolerated and has the potential to correct preoperative anaemia in a shorter period of time. This reflected in shortening the period of stay in the hospital with fewer amounts of transfused PRBCs units as well as improvement in symptoms of anaemia. The benefits extended to the post operative follow up period. There was also a considerable amount of cost saving in patients whom received IV iron. Further randomised trials are warranted to address the important issue with preoperative anaemia that significantly affects the already overstretched health budget and compromises the outcome of elective surgery especially in view of short blood supplies. A suggested treatment algorithm or management pathway of preoperative anaemia was discussed in some studies [31,32]. Furthermore, our study has a few shortcomings; first due to the relatively small number of patients studied owing to the technical difficulties to recruit the patients, which is ideally $3-4$ weeks prior to surgery, it is hard to draw firm conclusions. However, it is worthwhile to publish these data as a reference due to paucity of clinical trials in this field. Second; the relatively short preoperative duration of treatment with oral iron in some patients, is arguably not sufficient to replete the iron stores. This perhaps proves the point for effectiveness of IV iron in replenishing the iron stores in a shorter period of time compared to oral iron as seen in other cohort of patients [25,33]. The IV iron group was also able to maintain the $\mathrm{Hb}$ for a longer period of time compared to oral iron. It is worth noting that there is lack of data regarding prospective randomised trials using IV iron in preoperative setting. Therefore it is worthwhile documenting the results of this cohort of patients as a basis for further research.

Certainly parenteral iron is considered as an attractive option for the treatment of IDA and is likely to be even more popular due to the introduction of new intravenous iron preparations (Table 2), which allow relatively high doses of iron to be administered rapidly in a single treatment. Recent reports demonstrate the feasibility of rapid iron polymaltose infusion over 90 minutes [33,34]. However, a test-dose of iron polymaltose $(100 \mathrm{mg}$ ) should be first administered over 30 minutes. Moreover, the new intravenous iron preparations represent a medical revolution in the effective, rapid and safe repletion of iron stores in the management of IDA and therefore should be considered in the new guidelines of management of IDA in different clinical scenarios [24,34]. This will create an effective and attractive solution in the management of IDA in different populations.

In summary, this study aligns and provides further supporting evidence for the ongoing debate regarding the peri-operative module of the Australian National Blood Authorities Patient Blood Management Guidelines [35]. In this sense, the NATA recommends screening of all elective orthopaedic surgical patients with full blood count 4 weeks prior to surgery with a target $\mathrm{Hb}$, before elective surgery, to be within the normal range, according to the WHO criteria [20]. Further investigations are recommended to evaluate anaemia for nutritional deficiencies, and or chronic renal insufficiency. NATA also recommends that nutritional deficiencies should be treated and substituted. Erythropoiesis-stimulating agents may be used for anaemic patients in whom nutritional deficiencies have been ruled out, corrected, or both [20].

Thus, a standard global guideline for management of preoperative anaemia should be implemented by the experts in the field and at the same time should be flexible to address patients and health professionals' requirements as well as considering the local health system accessibility for the best possible outcome.

\section{Acknowledgements}

The authors wish to thank the Head of Department of Medicine, Dr Alasdair MacDonald and the CEO of the Launceston General Hospital, Mr John Kirwan for 
Citation: Khalafallah A, Al-Barzan AM, Chan J, Sung MF, Bates G, et al. (2012) A Prospective Randomized Controlled Trial to Assess the Effect of Intravenous versus Oral Iron Therapy in the Treatment of Orthopaedic Preoperative Anaemia. J Blood Disorders Transf 3:127. doi:10.4172/2155-9864.1000127

their continuous support in conducting this research.

\section{References}

1. Spahn DR (2010) Anemia and patient blood management in hip and knee surgery: a systematic review of the literature. Anesthesiology 113: 482-495.

2. Patel MS, Carson JL (2009) Anemia in the preoperative patient. Med Clin North Am 93: 1095-1104.

3. Beris P, Muñoz M, García-Erce J A, Thomas D, Maniatis A, et al. (2008) Perioperative anaemia management: consensus statement on the role of intravenous iron. Br J Anaesth 100: 599-604

4. Spahn DR (2010) Anemia and patient blood management in hip and knee surgery. a systematic review of the literature. Anesthesiology 113: 482-495

5. Dunne JR, Malone D, Tracy JK, Gannon C, Napolitano LM (2002) Perioperative anemia: an independent risk factor for infection, mortality, and resource utilization in surgery. J Surg Res 102: 237-244.

6. Karkouti K, Wijeysundera DN, Beattie WS (2008) Risk associated with preoperative anemia in cardiac surgery: a multicentre cohort study. Circulation 117: 478-484.

7. Kulier A, Levin J, Moser R, Rumpold-Seitlinger G, Tudor IC, et al. (2007) Impact of preoperative anemia on outcome in patients undergoing coronary artery bypass graft surgery. Circulation 116: 471-479.

8. Ferraris VA, Davenport DL, Saha SP, Austin PC, Zwischenberger JB (2012) Surgical outcomes and transfusion of minimal amounts of blood in the operating room. Arch Surg 147: 49-55.

9. O'Keeffe SD, Davenport DL, Minion DJ, Sorial EE, Endean ED, et al. (2010) Blood transfusion is associated with increased morbidity and mortality after lower extremity revascularization. J Vasc Surg 51: 616-621.

10. Isbister JP, Shander A, Spahn DR, Erhard J, Farmer SL, et al. (2011) Adverse blood transfusion outcomes: establishing causation. Transfus Med Rev 25: 89101.

11. Garg M, Morrison G, Friedman A, Lau A, Lau D, et al. (2011) A rapid infusion protocol is safe for total dose iron polymaltose: time for change. Intern Med $J$ 41: $548-554$

12. Mauermann WJ, Shilling AM, Zuo Z (2006) A comparison of neuraxial block versus general anesthesia for elective total hip replacement: a meta-analysis. Anesth Analg 103: 1018-1025.

13. Hurst NP, Ruta DA, Kind P (1998) Comparison of the MOS short form-12 (SF12) health status questionnaire with the SF36 in patients with rheumatoid arthritis. Br J Rheumatol 37: 862-869.

14. Ware J Jr, Kosinski M, Keller SD (1996) A 12-Item Short-Form Health Survey: construction of scales and preliminary tests of reliability and validity. Med Care 34: $220-233$

15. Shander A, Hofmann A, Ozawa S, Theusinger OM, Gombotz H, et al. (2010) Activity-based costs of blood transfusions in surgical patients at four hospitals. Transfusion 50: 753-765

16. Shander A, Hofmann A, Gombotz H, Theusinger OM, Spahn DR (2007) Estimating the cost of blood: past, present, and future directions. Best Pract Res Clin Anaesthesiol 21: 271-289.

17. Bierbaum BE, Callaghan JJ, Galante JO, Rubash HE, Tooms RE, et al (1999) An analysis of blood management in patients having a total hip or knee arthroplasty. J Bone Joint Surg Am 81: 2-10.

18. Shander A, Knight K, Thurer R, Adamson J, Spence R (2004) Prevalence and outcomes of anemia in surgery: a systematic review of the literature. Am J Med 116: 58S-69S

19. Goodnough LT, Shander A, Spivak JL, Waters JH, Friedman AJ, et al. (2005) Detection, evaluation, and management of anemia in the elective surgical patient. Anesth Analg 101: 1858-1861.

20. Goodnough LT, Maniatis A, Earnshaw P, Benoni G, Beris P, et al. (2011) Detection, evaluation, and management of preoperative anaemia in the elective orthopaedic surgical patient: NATA guidelines. Br J Anaesth 106: 13-22.

21. Beattie WS, Karkouti K, Wijeysundera DN, Tait G (2009) Risk associated with preoperative anemia in noncardiac surgery: A single-center cohort study. Anesthesiology 110: 574-581.
22. Patel MS, Carson JL (2009) Anemia in the preoperative patient. Med Clin North Am 93: 1095-1104

23. Goddard AF, James MW, McIntyre AS, Scott BB (2011) Guidelines for the management of iron deficiency anaemia. Gut 60: 1309-1316.

24. Muñoz M, García-Erce JA, Cuenca J, Bisbe E, Naveira E (2012) On the role of iron therapy for reducing allogeneic blood transfusion in orthopaedic surgery. Blood Transfus 10: 8-22.

25. Bisbe E, García-Erce JA, Díez-Lobo Al, Muñoz M (2011) A multicentre comparative study on the efficacy of intravenous ferric carboxymaltose and iron sucrose for correcting preoperative anaemia in patients undergoing major elective surgery. $\mathrm{Br} \mathrm{J}$ Anaesth 107: 477-478.

26. Moonen AF, Thomassen BJ, Knoors NT, van Os JJ, Verburg AD, et al. (2008) Pre-operative injections of epoetin-alpha versus post-operative retransfusion of autologous shed blood in total hip and knee replacement: a prospective randomised clinical trial. J Bone Joint Surg Br 90: 1079-1083.

27. Keating EM, Callaghan JJ, Ranawat AS, Bhirangi K, Ranawat CS (2007) A randomized, parallel-group, open-label trial of recombinant human erythropoietin vs preoperative autologous donation in primary total joint arthroplasty: effect on postoperative vigor and handgrip strength. J Arthroplasty 22: $325-333$

28. Cuenca J, Garcia-Erce JA, Martinez F, Cardona R, Perez-Serrano L, et al. (2007) Preoperative haematinics and transfusion protocol reduce the need for transfusion after total knee replacement. Int J Surg 5: 89-94.

29. Garcia-Erce JA, Cuenca J, Martinez F, Cardona R, Perez-Serrano L, et al. (2006) Perioperative intravenous iron preserves iron stores and may hasten the recovery from post-operative anaemia after knee replacement surgery. Transfus Med 16: 335-341

30. Garcia-Erce JA, Cuenca J, Muñoz M, Izuel M, Martinez AA, et al. (2005 Perioperative stimulation of erythropoiesis with intravenous iron and erythropoietin reduces transfusion requirements in patients with hip fracture. A prospective observational study. Vox Sang 88: 235-243

31. Theusinger OM , Leyvraz PF, Schanz U, Seifert B, Spahn DR (2007) Treatment of iron deficiency anemia in orthopedic surgery with intravenous iron: efficacy and limits a prospective study. Anesthesiology 107: 923-927.

32. Pape A, Habler O (2007) Alternatives to allogeneic blood transfusions. Best Pract Res Clin Anaesthesiol 21: 221-239.

33. Khalafallah A, Dennis A, Bates J, Bates G, Robertson IK, et al. (2010) A prospective randomized, controlled trial of intravenous versus oral iron for moderate iron deficiency anaemia of pregnancy. J Intern Med 268: 286-295.

34. Khalafallah AA, Dennis AE (2012) Iron deficiency anaemia in pregnancy and postpartum: pathophysiology and effect of oral versus intravenous iron therapy. J Pregnancy 2012: 630519.

35. Australian National Blood Authority (2012) Patient blood management guidelines: Module 2 - Perioperative anaemia 